\title{
Kinetics and Mechanism of Oxidation of Creatine by N-Bromosuccinimide in Acidic Aqueous Medium
}

\author{
NasmaDafalla Eljack, ${ }^{1,2}$ Ehab MubarakIbrahim,,$^{2 *}$ Malik Abdalla Elsheikh ${ }^{1}$ \\ and Mohammed Tarahib Alotaibi ${ }^{1}$
}
${ }^{1}$ Department of Chemistry, Turabah University College, Taif University, Saudi Arabia
${ }^{2}$ Department of Chemistry, Faculty of Science, University of Khartoum, Sudan
${ }^{*}$ Corresponding author: malikabdalla@yahoo.com

Published online: 25 November 2020

To cite this article: Eljack, N.D. et al. (2020). Kinetics and mechanism of oxidation of creatine by N-Bromosuccinimide in acidic aqueous medium. J. Phys. Sci., 31(3), 61-72. https://doi.org/10.21315/jps2020.31.3.5

To link to this article: https://doi.org/10.21315/jps2020.31.3.5

\begin{abstract}
The kinetics and the mechanism of oxidation of creatine (AA) by $N$-Bromosuccinimide (NBS) in an acidic aqueous medium were examined under isolation conditions. Iodometric method was used to follow the unconsumed NBS at different time intervals. Mercuric(II) acetate was used as a scavenger to capture any Br formed during the reaction and hence to avoid autocatalytic oxidation by bromine. Findings from stoichiometry measurements revealed that the reaction between AA and NBS was a 2:1 molar ratio. The kinetic study showed that the reaction was first order with respect to both $A A$ and NBS. Increasing $\left[\mathrm{H}^{+}\right]$had a negative effect on the rate of reaction. The effect that varying the solvent composition has on the rate of reaction was investigated, and it was found that the reaction rate decreased as the dielectric constant of the solvent increased. The temperature dependence was determined under fixed experimental conditions, from which thermodynamic parameters were calculated. From the proposed mechanism, a rate law was established that was in strong agreement with experimental kinetics.
\end{abstract}

Keywords: Kinetics, iodometric, creatine, N-Bromosuccinimide, oxidation

\section{INTRODUCTION}

N-Bromosuccinimide (NBS) is one of the oxidants that is widely used in oxidising organic compounds. ${ }^{1-5}$ It is also used to oxidise many inorganic complexes, as well as biochemical compounds. ${ }^{6-2} \mathrm{NBS}$ is a source of positive halogen, and this reagent has been exploited as an oxidant for a variety of substrates in neutral, acidic and alkaline mediums. NBS has also been used as a reagent in the determination of 
some chemical compounds. For example, Haiyan et al. determined meloxicam by oxidation with NBS using the flow-injection chemiluminescence technique, and the same technique was used to determine urea. ${ }^{13,14}$ Fluorometric assays carried out by Lee et al. for commercial NBS indicated that NBS reagents could be assayed rapidly using a convenient method. ${ }^{15} \mathrm{Xu}$ et al. used NBS for the oxidation of indoles to produce different pharmaceutically valuable nitrogen compounds. ${ }^{16}$

The oxidation of amino acids is of interest as the oxidation products depend on the oxidant used. These oxidation reactions exhibit diverse reaction mechanisms, oxidative deamination and decarboxylation. ${ }^{17}$ Thus, the study of amino acids becomes important due to their biological significance and selectivity towards the oxidant.

Singh et al. studied the kinetic oxidation of some amino acid by NBS and they found that the reaction obeys first-order with respect to the amino acid under study. ${ }^{18}$ Linge Gowda et al. studied the oxidation of dipeptides and their amino acids by NBS, and the result they obtained indicated that the reaction obeys first-order kinetic. ${ }^{19}$ A kinetic study and the determination of the thermodynamic parameters of $\alpha$-amino acids (proline, arginine, alanine) oxidised by NBS were carried out by Mohammed and Hadi, and the results obtained indicated that for both oxidation of creatine (AA) and NBS the reaction was first-order. ${ }^{20}$ A kinetic study of the oxidative cleavage reaction of gabapentin with NBS conducted by Bhandarkar and Mohana indicated that the reaction was a first-order kinetic reaction. ${ }^{21}$ Yadav et al. studied the oxidation of L-valine by NBS and found the reaction was a first-order kinetics reaction with respect to L-valine. ${ }^{22}$ There were also other systems involved in NBS as an oxidising agent in amino acid oxidation that exhibited second and fractional order kinetics.

There are many reports in the literature regarding the oxidation of amino acids, but the kinetics of the oxidation of creatine by NBS have not yet been reported. ${ }^{23-25}$ The main objective of this work is to study of the kinetics and the mechanism of the oxidation of creatine by NBS in an acetic medium and as well as to investigate the effect of different experimental variables on the reaction rate.

\section{EXPERIMENTAL}

\subsection{Materials}

The following materials were used in this study: N-Bromosuccinimide, creatine, sodium thiosulphate, potassium iodide, mercuric acetate, perchloric acid, sodium perchlorate, methanol and starch. All chemicals used were BDH or reagent grade 
quality and were used as received without further purification. Fresh distilled water was employed in all chemical preparations and kinetics experiments.

\subsection{Kinetic Procedure}

All experiments were carried out under first-order conditions, where the amino acid concentration exceeded that of oxidant. In these experiments, appropriate amounts of the substrate, perchloric acid, sodium perchlorate solution and distilled water (to keep the total volume constant at $50 \mathrm{ml}$ in a volumetric flask for all runs) were taken in the reaction vessel and thermostated at the desired temperature to attain thermal equilibrium. A separately thermostated NBS solution was rapidly transferred to the reaction mixture. The progress of the reaction was monitored iodometrically by assaying the unreacted NBS in a measured aliquot of the reaction mixture at different time intervals. This was done by pipetting $5 \mathrm{ml}$ aliquots of the reaction mixture and discharging it into a conical flask containing $5 \mathrm{ml}$ of $0.1 \mathrm{M} \mathrm{Kl}$ and $5 \mathrm{ml}$ of $0.1 \mathrm{M} \mathrm{H}_{2} \mathrm{SO}_{4}$. The liberated iodine was then titrated against a standard solution of $0.2 \mathrm{M}$ sodium thiosulphate using starch as an internal indicator near the endpoint.

\section{RESULTS AND DISCUSSION}

\subsection{Stoichiometry}

Stoichiometric measurements were taken by carrying different sets of reaction mixtures containing different amounts of NBS and creatine at a constant concentration of $\left[\mathrm{H}^{+}\right]$and a constant ionic strength. This mixture was left to react for about $24 \mathrm{~h}$ at $25^{\circ} \mathrm{C}$. After the reaction was complete, the remaining NBS was assayed iodometrically. Figure 1 shows the progress of the reaction as [NBS] decreased with time.

The main final products of the oxidation were succinimide, formaldehyde, ammonia and carbon dioxide. As the spectra of these are well known, spot tests were conducted to confirm the following products:

- Librated ammonia was identified by Nessler's reagent

- Carbon dioxide was identified by the lime water test

- Aldehyde group was confirmed with Tollen's reagent 


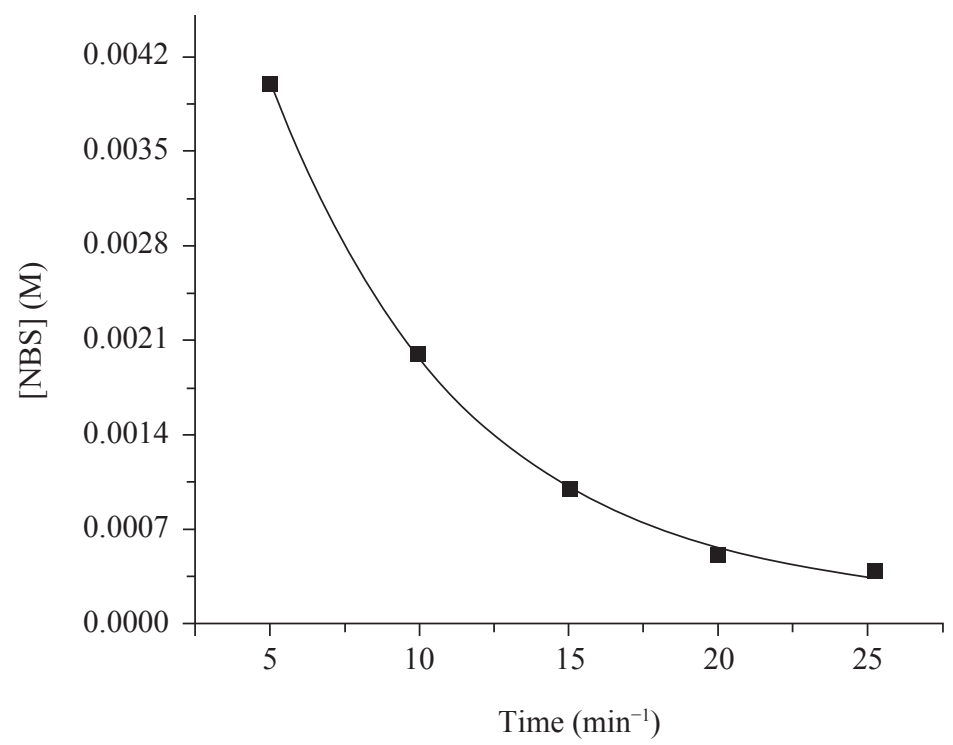

Figure 1: The progress of creatine-NBS reaction at $[\mathrm{NBS}]=5.0 \times 10^{-3} \mathrm{M},[\mathrm{AA}]=5.0 \times$ $10^{-2} \mathrm{M},\left[\mathrm{H}^{+}\right]=0.1 \mathrm{M}$ and at $\left[\mathrm{Hg}(\mathrm{OAc})_{2}\right]=0.02 \mathrm{M}$ and $\mathrm{T}=25^{\circ} \mathrm{C}$.

The results in Table 1 indicate that every two moles of AA were consumed by one mole of NBS. Accordingly, the stoichiometric equation reaction between protonated NBS $\left(\mathrm{C}_{4} \mathrm{H}_{4} \mathrm{BrNO}_{2}\right)$ and creatine $\left(\left(\mathrm{H}_{2} \mathrm{~N}\right)(\mathrm{HN}) \mathrm{CN}\left(\mathrm{CH}_{3}\right) \mathrm{CH}_{2} \mathrm{COOH}\right)$ was as follows:

$$
\begin{aligned}
& \mathrm{C}_{4} \mathrm{H}_{4} \mathrm{BrNO}_{2}+2\left(\mathrm{H}_{2} \mathrm{~N}\right)(\mathrm{HN}) \mathrm{CN}\left(\mathrm{CH}_{3}\right) \mathrm{CH}_{2} \mathrm{COOH}+2 \mathrm{H}_{2} \mathrm{O} \\
& +\mathrm{H}^{+} \longrightarrow \mathrm{C}_{4} \mathrm{HO}_{2}+2 \mathrm{CH}_{2} \mathrm{O}+2 \mathrm{CH}_{3} \mathrm{CN}+2 \mathrm{CO}_{2}+1 / 2 \mathrm{Br}_{2} \\
& +4 \mathrm{NH}_{3}
\end{aligned}
$$

Table 1: Stoichiometry of NBS oxidation of creatine in aqueous acidic medium at $25^{\circ} \mathrm{C}$, $\left[\mathrm{H}^{+}\right]=0.10,\left[\mathrm{Hg}(\mathrm{OAc})_{2}\right]=0.02, \mathrm{I}=0.30 \mathrm{~mol} \mathrm{dm}{ }^{3}$.

\begin{tabular}{cccc}
\hline Exp. no. & Conc. $10^{3}[\mathrm{AA}] \mathrm{M}^{*}$ & Conc. $10^{3}[\mathrm{NBS}] \mathrm{M}^{*}$ & $\begin{array}{c}\text { No. of moles of NBS } \\
\text { unconsumed }\end{array}$ \\
\cline { 2 - 3 } 1 & AA taken & NBS added & 2.02 \\
2 & 3.0 & 2.0 & 2.05 \\
3 & 4.0 & 4.0 & 2.03 \\
4 & 5.0 & 6.0 & 2.01 \\
\hline
\end{tabular}

Note: ${ }^{*}$ No. of $m l=$ number of moles 


\subsection{Effect of NBS on the Reaction Rate}

The variation of [NBS] was carried out at fixed reaction conditions. Plots of log [NBS] versus time were linear as seen in Figure 2 with correlation coefficients in the range of $0.98-0.99$, values of pseudo first-order rate constants, $\mathrm{k}_{\mathrm{obs}}\left(\mathrm{min}^{-1}\right)$ were calculated from the slope of these graphs. It is clear that from Table 2, the values of $\mathrm{k}_{\text {obs }}$ obtained are independent of NBS concentrations. This is in agreement with a first-order dependence on the concentration NBS. Thus, the rate law is given by Equation 1:

$$
\mathrm{R}=\mathrm{k}_{\mathrm{obs}}[\mathrm{NBS}]
$$

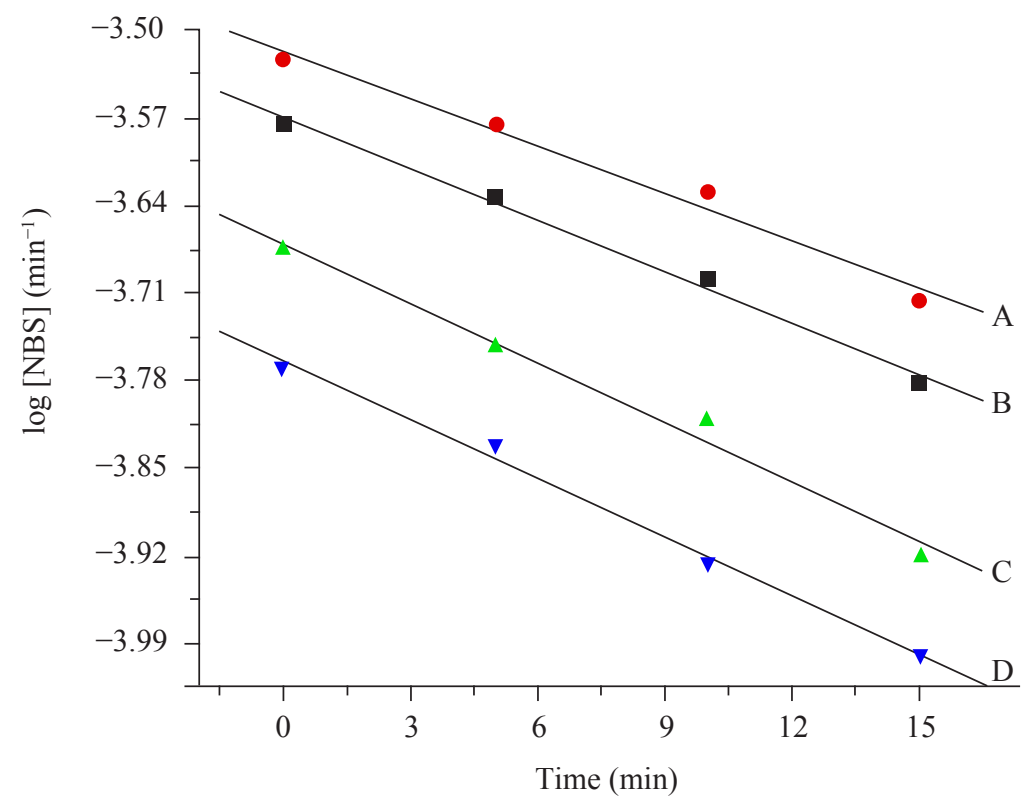

Figure 2: Plot of $\log [\mathrm{NBS}](\mathrm{M})$ vs. time $(\min )$ at $[\mathrm{AA}]=5.0 \times 10^{-2} \mathrm{M},\left[\mathrm{H}^{+}\right]=0.1 \mathrm{M}$ and at $\left[\mathrm{Hg}(\mathrm{OAc})_{2}\right]=0.02 \mathrm{M}$, and $\mathrm{T}=25^{\circ} \mathrm{C}, \mathrm{A}[\mathrm{NBS}]=5.0 \times 10^{-3} \mathrm{M}$, $\mathrm{B}[\mathrm{NBS}]=4.0 \times 10^{-3} \mathrm{M}, \mathrm{C}[\mathrm{NBS}]=2.0 \times 10^{-3} \mathrm{M}$ and $\mathrm{D}[\mathrm{NBS}]=1.0 \times 10^{-3} \mathrm{M}$.

\subsection{Effect of Creatine on the Reaction Rate}

The variation of amino acid AA concentrations on the rate of the reaction was investigated over the range of $1.0-10.0 \times 10^{-2} \mathrm{M}$ at constant reaction conditions (Table 2). Pseudo first-order rate constants obtained were found to increase with increasing [AA] as shown in Table 2. A plot of $\log \mathrm{k}_{\mathrm{obs}} \mathrm{vs.} \log [\mathrm{AA}]$ was a straight line with slope $=0.98 \pm 0.02$, showing that the reaction obeys first order with respect to $[\mathrm{AA}]$ as shown in Figure 3. 
Table 2: Kinetic data for the oxidation of creatine by NBS at $\left[\mathrm{Hg}(\mathrm{OAc})_{2}\right]=0.02 \mathrm{M}$ and $\mathrm{T}=25^{\circ} \mathrm{C}$ (all kinetic runs were performed in aqueous perchloric media otherwise stated).

\begin{tabular}{|c|c|c|c|c|}
\hline $10^{3}[\mathrm{NBS}] \mathrm{M}$ & $10^{2}[$ creatine $] \mathrm{M}$ & {$\left[\mathrm{H}^{+}\right] \mathrm{M}$} & Ethanol:Water & $10^{3} \mathrm{k}_{\mathrm{obs}} \min ^{-1}$ \\
\hline 0.5 & 5.0 & 0.10 & & $9.1 \pm 0.03$ \\
\hline 1.0 & & & & $9.3 \pm 0.05$ \\
\hline 2.0 & & & & $8.9 \pm 0.01$ \\
\hline 3.0 & & & & $9.0 \pm 0.02$ \\
\hline 5.0 & & & & $9.2 \pm 0.02$ \\
\hline \multirow[t]{12}{*}{1.0} & 1.0 & & & $3.9 \pm 0.06$ \\
\hline & 3.0 & & & $7.2 \pm 0.03$ \\
\hline & 5.0 & & & $10.4 \pm 0.04$ \\
\hline & 7.0 & & & $12.4 \pm 0.02$ \\
\hline & 10.0 & & & $13.9 \pm 0.04$ \\
\hline & 0.5 & 0.20 & & $7.1 \pm 0.08$ \\
\hline & & 0.30 & & $5.4 \pm 0.05$ \\
\hline & & 0.50 & & $3.6 \pm 0.02$ \\
\hline & & 1.00 & & $2.7 \pm 0.01$ \\
\hline & & 0.10 & $5: 95$ & $14.73 \pm 0.05$ \\
\hline & & & $10: 90$ & $7.91 \pm 0.03$ \\
\hline & & & $15: 85$ & $3.08 \pm 0.02$ \\
\hline
\end{tabular}

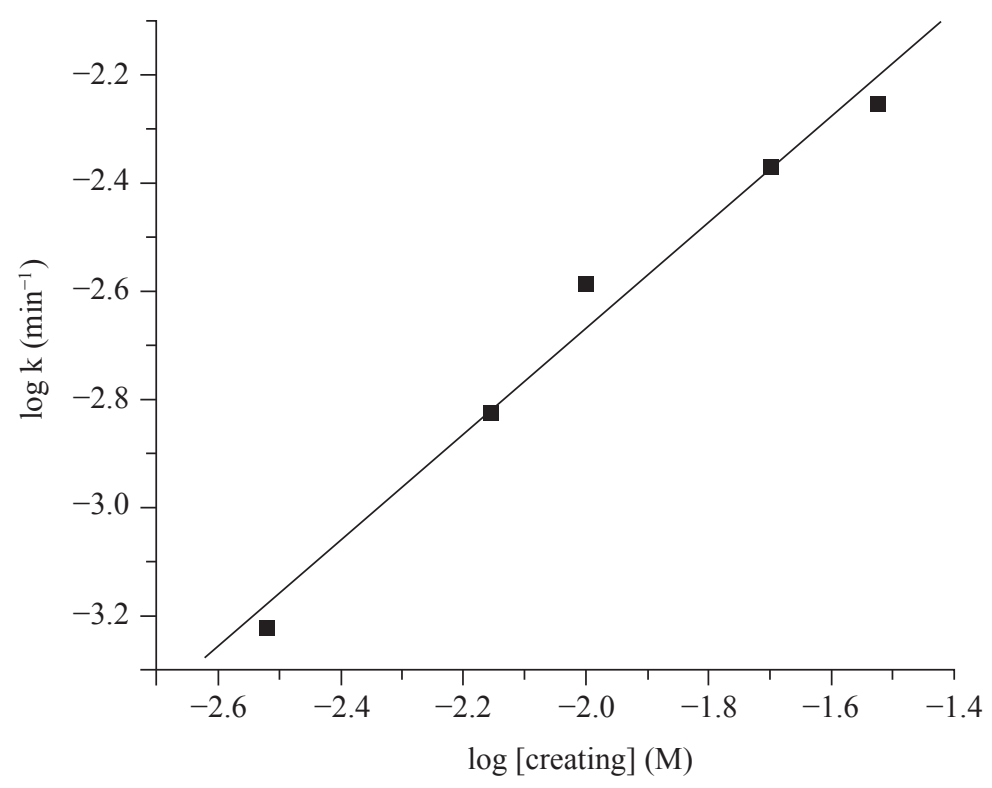

Figure 3: Plot of $\log \mathrm{k}_{\mathrm{obs}}$ vs. $\log [\mathrm{AA}](\mathrm{M})$ at $[\mathrm{NBS}]=2.0 \times 10^{-3} \mathrm{M},\left[\mathrm{H}^{+}\right]=0.1 \mathrm{M}$ and at $\left[\mathrm{Hg}(\mathrm{OAc})_{2}\right]=0.02 \mathrm{M}$ and $\mathrm{T}=25^{\circ} \mathrm{C}$. 


\subsection{Effect of $\left[\mathrm{H}^{+}\right]$on the Reaction Rate}

The influence of $\left[\mathrm{H}^{+}\right]$was investigated by using different concentrations of perchloric acid while keeping other variables constant (Table 2). The results indicated that the rate of the reaction decreased with increasing $\left[\mathrm{H}^{+}\right]$. This inverse dependence on acid concentration is due to the fact that the unprotonated species is the reactive one.

\subsection{Effect of Solvent Composition on the Reaction Rate}

In order to determine the effect of the dielectric constant of the medium on the reaction rate, the oxidation of creatine by NBS was studied in aqueous-methanol mixtures of various compositions as shown in Table 2. The rate of the reaction decreased with increasing percentage of methanol in the mixture. In other words, a decrease in the dielectric constant of the medium lowers the rate of reaction. This indicates that there is a charge development in the transition state involving a more polar activated complex than the reactants..$^{26,27}$

\subsection{Effect of Temperature on the Reaction Rate}

The oxidation of creatine by NBS was carried out at different temperatures in the range of 298-323 $\mathrm{K}$ under constant reaction conditions, thermodynamic parameters; energy of activation $\left({ }^{\ddagger} \Delta \mathrm{E}\right)$, enthalpy change $\left({ }^{*} \Delta \mathrm{H}\right)$, entropy change $\left({ }^{\star} \Delta \mathrm{S}\right)$ and free energy change $\left({ }^{\star} \Delta \mathrm{G}\right)$ were calculated and these data were collected in Table 3 using Arrheneous (Equation 2) and Erying equation (Equation 3):

$$
\begin{aligned}
& \ln \mathrm{k}=\ln \mathrm{A}-\mathrm{Ea} / \mathrm{RT} \\
& \ln \mathrm{k} / \mathrm{T}=-\Delta \mathrm{H}^{\ddagger} / \mathrm{R} \cdot 1 / \mathrm{T}+\ln \mathrm{k}_{\mathrm{B}} / \mathrm{h}+\Delta \mathrm{S} / \mathrm{R}
\end{aligned}
$$

The data were well fitted into these equations with the output illustrated in Figures 4 and 5.

Table 3: Temperature variation and thermodynamic parameters for the oxidation reaction between creatine and NBS at $[\mathrm{NBS}]=2.0 \times 10^{-3} \mathrm{M},[\mathrm{AA}]=2.0 \times$ $10^{-2} \mathrm{M},\left[\mathrm{H}^{+}\right]=0.2 \mathrm{M}$ and at $\left[\mathrm{Hg}(\mathrm{OAc})_{2}\right]=0.02 \mathrm{M}$.

\begin{tabular}{ccccccc}
\hline $\begin{array}{c}\text { Exp. } \\
\text { no. }\end{array}$ & $\begin{array}{c}\text { Temp. } \\
(\mathrm{K})\end{array}$ & $\begin{array}{c}10^{3} \mathrm{k}_{\text {obs }} \\
\left(\mathrm{min}^{-1}\right)\end{array}$ & $\begin{array}{c}\mathrm{Ea} \\
\left(\mathrm{kJ} \mathrm{mol}^{-1}\right)\end{array}$ & $\begin{array}{c}\Delta \mathrm{H} \\
\left(\mathrm{kJ} \mathrm{mol}^{-1}\right)\end{array}$ & $\begin{array}{c}\Delta \mathrm{S} \\
\left(\mathrm{JK}^{-1} \mathrm{~mol}^{-1}\right)\end{array}$ & $\begin{array}{c}\Delta \mathrm{S} \\
\left(\mathrm{JK}^{-1} \mathrm{~mol}^{-1}\right)\end{array}$ \\
\hline 1 & 283 & 7.1 & $35.15 \pm 1.0$ & $148.74 \pm 7.0$ & $-20.37 \pm 2.0$ & $57.78 \pm 30$ \\
2 & 298 & 15.51 & & & & \\
3 & 313 & 17.12 & & & & \\
4 & 323 & 3828 & & & & \\
\hline
\end{tabular}




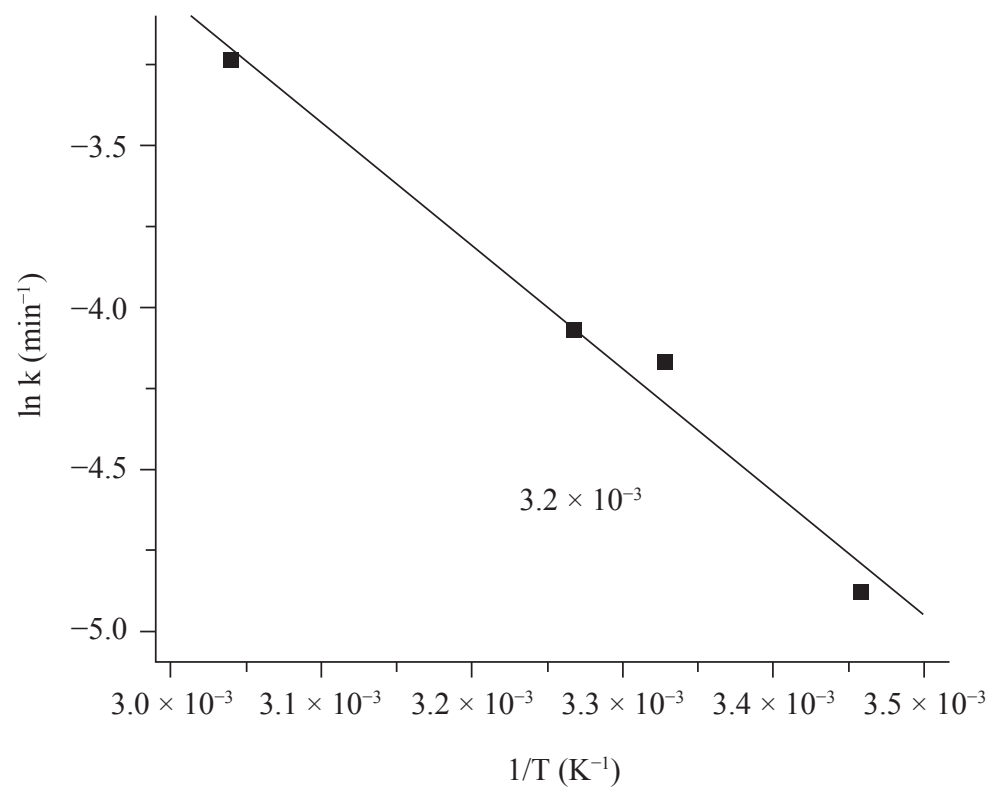

Figure 4: Plot of $\ln \mathrm{k}\left(\mathrm{min}^{-1}\right)$ vs. $1 / \mathrm{T}\left(\mathrm{K}^{-1}\right)$ at $[\mathrm{NBS}]=2.0 \times 10^{-3} \mathrm{M},[\mathrm{AA}]=2.0 \times 10^{-2} \mathrm{M}$, $\left[\mathrm{H}^{+}\right]=0.1 \mathrm{M}$ and at $\left[\mathrm{Hg}(\mathrm{OAc})_{2}\right]=0.02 \mathrm{M}$.

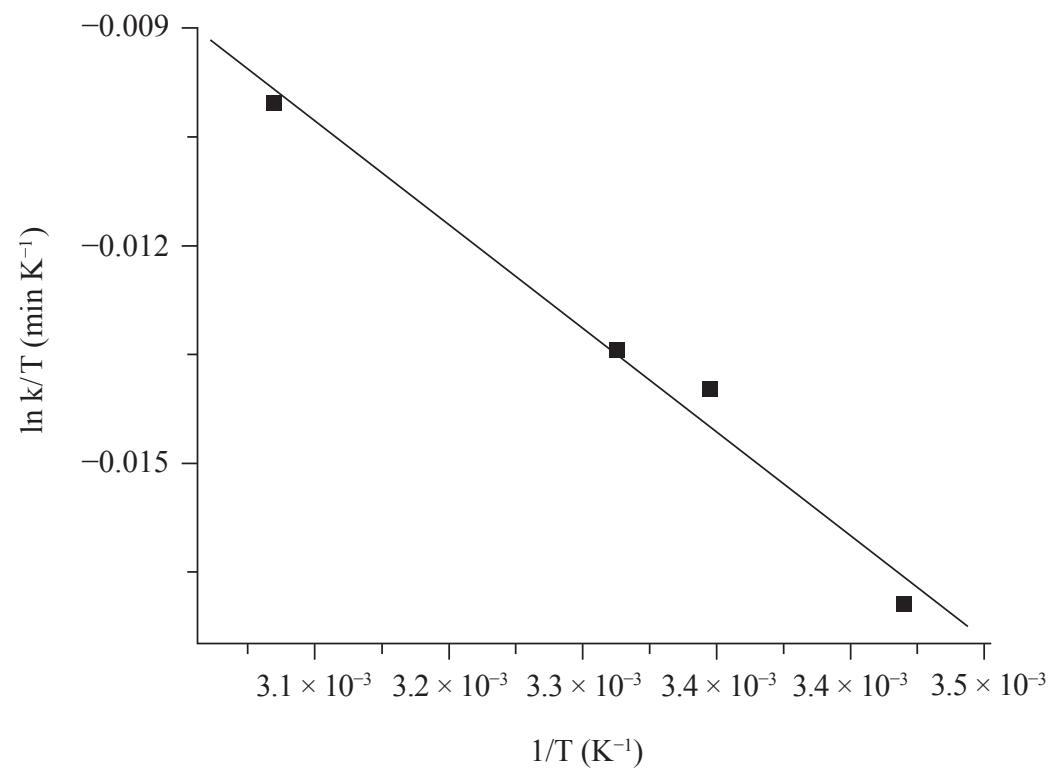

Figure 5: Plot of $\ln \mathrm{k} / \mathrm{T}\left(\min \mathrm{K}^{-1}\right)$ vs. $1 / \mathrm{T}\left(\mathrm{K}^{-1}\right)$ at $[\mathrm{NBS}]=2.0 \times 10^{-3} \mathrm{M},[\mathrm{AA}]=2.0 \times$ $10^{-2} \mathrm{M},\left[\mathrm{H}^{+}\right]=0.1 \mathrm{M}$ and at $\left[\mathrm{Hg}(\mathrm{OAc})_{2}\right]=0.02 \mathrm{M}$. 
The negative value of entropy was obtained, which can be attributed to the severe restriction of solvent molecules around the transition state. It also indicates that the complex is more ordered than the reactants.

Analysis of the experimental data from the regression line was carried out using Orgin 7.0 computer programme.

\subsection{Mechanism and the Rate Law of the Reaction}

In acidic media, NBS undergoes protonation as follows:<smiles>O=C1CCC(=O)N1Br</smiles>

NBS

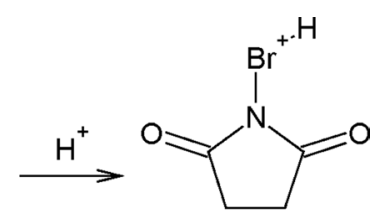

Hence the reaction between protonated NBS and creatine will be as follows:

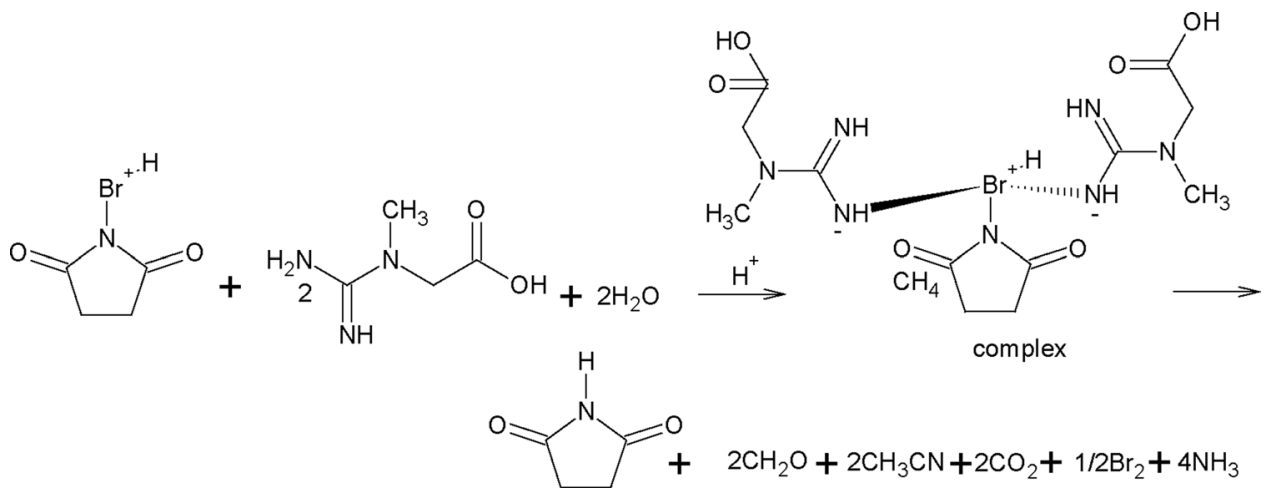

$$
\begin{array}{lc}
\mathrm{NBS}+\mathrm{H}^{+} \leftrightarrow \mathrm{NBSH}^{+} & \mathrm{K}_{1}=\left[\mathrm{NBSH}^{+}\right] /\left[\mathrm{H}^{+}\right][\mathrm{NBS}] \\
\mathrm{AA}+\mathrm{NBS} \leftrightarrow \text { AANBS } & \mathrm{K}_{2}=[\mathrm{AANBS}] /[\mathrm{AA}][\mathrm{NBS}] \\
\mathrm{AA}+\mathrm{NBSH}^{+} \leftrightarrow \mathrm{AANBSH}^{+} \mathrm{AAN}_{3}=\left[\mathrm{AANBSH}^{+}\right] /[\mathrm{AA}]\left[\mathrm{NBSH}^{+}\right]
\end{array}
$$

AANBS $\rightarrow$ Products $\mathrm{k}$

From the above mechanism, we can derive a rate law:

$$
\mathrm{R}=\mathrm{k}[\mathrm{AANBS}]=\mathrm{k} \mathrm{K}_{2}[\mathrm{AA}][\mathrm{NBS}]
$$


As the rate of oxidation is suppress by $\left[\mathrm{H}^{+}\right]$, the unprotonated NBS is the reactive species.

The total $[\mathrm{AA}]$ can be described by Equation 9:

$$
\begin{aligned}
{[\mathrm{AA}]_{\mathrm{T}} } & =[\mathrm{AA}]+[\mathrm{AANBS}]+\left[\mathrm{AANBSH}^{+}\right] \\
& =[\mathrm{AA}]+\mathrm{K}_{2}[\mathrm{AA}][\mathrm{NBS}]+\mathrm{K}_{3}[\mathrm{AA}][\mathrm{NBS}]\left[\mathrm{H}^{+}\right] \\
& =[\mathrm{AA}]\left\{1+\left(\mathrm{K}_{2}+\mathrm{K}_{3}\left[\mathrm{H}^{+}\right]\right)[\mathrm{NBS}]\right\} \\
{[\mathrm{AA}] } & =[\mathrm{AA}]_{\mathrm{T}} /\left\{1+\left(\mathrm{K}_{2}+\mathrm{K}_{3}\left[\mathrm{H}^{+}\right]\right)[\mathrm{NBS}]\right\}
\end{aligned}
$$

Substituting Equation 12 into Equation 8 yields Equation 13:

$$
\mathrm{R}=\mathrm{k} \mathrm{K}_{2}[\mathrm{AA}]_{\mathrm{T}}[\mathrm{NBS}] /\left\{1+\left(\mathrm{K}_{2}+\mathrm{K}_{3}\left[\mathrm{H}^{+}\right]\right)[\mathrm{NBS}]\right\}
$$

Because of low concentration of NBS, it can be omitted from the dominator and Equation 13 can be written as:

$$
\mathrm{R}=\mathrm{k} \mathrm{K}_{2}[\mathrm{AA}]_{\mathrm{T}}[\mathrm{NBS}] /\left\{1+\left(\mathrm{K}_{2}+\mathrm{K}_{3}\left[\mathrm{H}^{+}\right]\right)\right\}
$$

The above mechanism is acceptable, and the rate law in Equation 14 is consistent with experimental results which are the first order in both substrate and oxidant and has inverse dependence on acidic media.

\section{CONCLUSION}

This study has reported the kinetics and mechanism of oxidation of creatine by NBS in acidic aqueous solution. The reaction between creatine and NBS is 1:2 stoichiometry. The oxidation is first-order with respect to both creatine and NBS and has negative dependence on perchloric acid concentration. These results agreed with all kinetic studies mentioned the literature between amino acids and NBS. From the proposed mechanism, a rate law was driven which was consistent with experimental data.

\section{ACKNOWLEDGEMENTS}

The authors acknowledge, with gratitude, the Department of Chemistry at Faculty of Science, Khartoum University, Sudan, where this work has taken place for technical support. 


\section{REFERENCES}

1. Subbarayappa, A. \& Paresh, P. (2007). N-Bromosuccinimide: A facile reagent for the oxidation of benzylic alcohols to aldehydes. Synth. Commun., 37(40), 15711577. https://doi.org/10.1080/00397910701239023

2. Singh, K et al. (1978). Kinetics and mechanism of oxidation of diethylketone by N-Bromosuccinimde. Inter. J. Chem. Kine., 10(9), 995-1002. https://doi.org/ 10.1002/kin.550100908

3. Saxena, R. et al. (1991). Kinetics and mechanism of the ruthenium(III)-catalyzed oxidation of hydroxy-acids by N-Bromosuccinimide. Int. J. Trans. Metal Chem., 16(2), 245-248.

4. Mavalangi, S. K. et al. (2001). Oxidation of ethylenediaminetetraacetic acid by N-Bromosuccinimide in aqueous alkaline medium - A kinetic study. Turk. J. Chem., 25, 355-363.

5. Pandey, S. \& Upadhyay, S. K. (2005). Effect of non-ionic micellar aggregates on the kinetic of oxoidation of aminoalcohols by N-Bromosuccinimide inalkaline medium. Ind. J. Chem. Tech., 11, 35-42.

6. Eljack, N. D. \& Sulfab, Y. (2011). Kinetics and mechanism of oxidation of aquaethylene diamine tetraacetatocobaltate(II) by N-Bromosuccinimide in aqueous solution. Trans. Met. Chem., 36, 87-91. https://doi.org/10.1007/s11243 -010-9438-y

7. Eljack N. D. \& Sulfab, Y. (2012). Kinetics of the biphasic oxidation of aqua ethylene diamine tetra acetatochromate(III) and cisdiaquabisin aqueous solutions: Formation of long lived chromium(IV) complexes. Polyhedr., 44, 28-33.

8. Eljack, N. D. \& Sulfab, Y. (2016). Biphasic oxidation of cis-diaquabis(1,10phenanthroline)chromium(III) by N-Bromosuccinimide and the formation of chromium(IV) and chromium(V). Inter. J. Chem. Kin., 48(4), 197-203. https://doi.org/10.1002/kin.20982

9. Abdel Khalek, A. A. et al. (2003). Kinetics and mechanism of the oxidation of a ternary complex involving nitrillotriacetatoco-baltate (II) and succinic acid by N-Bromosuccinimde. Inter. J. Trans. Metal Chem., 28(6), 635-639. https://doi.org/10.1023/A:1025450110292

10. Abdel Khalek, A. A. et al. (2004). Kinetics and mechanism of the oxidation of a ternary complex involving nitrillotriacetato cobltate(II) and malonic acid by N-Bromosuccinimide. Int. J. Trans. Metal Chem., 29(1), 7-11. https://doi.org/10 .1023/B:TMCH.0000014473.02414.f3

11. Inokuchi, V. et al. (1982). N-Bromosuccinimide oxidation of a glucoamylase from aspergillussaitoi. J. Biochem., 91(5), 1661-1668.

12. Ramachandrappa, R. et al. (1998). Kinetics and mechanism of oxidation of aspirin by bromamine-T, N-bromosuccinimide, and N-bromophthalimide. Int. J. Chem. Kin., 30(6), 407-414. https://doi.org/10.1002/(SICI)1097-4601(1998)30 :6\%3C407::AID-KIN2\%3E3.0.CO;2-W.

13. Haiyan, L. et al. (2005). Flow-injection chemiluminescence determination of meloxicam by oxidation with N-bromosuccinimide. Anal. Chim. Acta, 541(1-2), 185-190. https://doi.org/10.1016/j.aca.2005.02.078. 
14. Baoxin, L. et al. (2001). Flow-injection chemiluminescence determination of urea by oxidation with N-bromosuccinimide. Anal. Let., 34(12), 2141-2151. https://doi.org/10.1081/AL-100106845

15. Lee, U. J. et al. (2019). Reaction-based fluorometric analysis of N-Bromosuccinimide by oxidative deprotection of dithiane. Anal., 144(10), 32673273. https://doi.org/10.1039/C8AN02125B

16. Xu, J. et al. (2019). Green oxidation of indols using halide catalysis. Nat. Commun., 10, 4754, 1-11. https://doi.org/ 10.1038/s41467-019-12768-4

17. Huo, S. et al. (2009). Mechanistic investigation of oxidation of glycine and alanine by bis(dihydrogen-tellurto)argentite(III) ion in alkaline medium: A kinetic study. J. Iran. Chem. Soc., 6(2), 243-250.

18. Singh, A. K. et al. (2012). Kinetic and mechanistic studies of oxidation of glycine and valine by N-Bromosuccinimide using chloro complex of Rh(III) in its nanoconcentration range as homogeneous catalyst. Ind. J. Chem., 51A, 681-689.

19. Linge Gowda, N. S. et al. (2006). N-Bromosuccinimide oxidation of dipeptides and their amino acids: Synthesis, kinetics and mechanistic studies. Int. J. Chem. Kin., 38(6), 376-385. https://doi.org/10.1002/kin.20161

20. Mohammed, A. J. \& Hadi, H. (2007). Kinetics and mechanism studies of oxidation of $\alpha$-amino acids by N-Bromosuccinimide. J. Al-Nahr. Univ., 10(2), $66-72$.

21. Bhandarkar, P. M. R. \& Mohana, K. N. (2009). Oxidative cleavage reaction of gabapentin with N-Bromosuccinimide in acid medium: A kinetics and mechanism study. Ind. J. Chem., 1107-1112.

22. Yadav, M. B. \& Dhan Raj, R. J. (2018). Kinetics and mechanism of palladium (II) catalysed oxidation of valine by N-Bromosuccinimide in perchloric acid medium. Int. J. Sci. Res. Method., 10(3), 131-147.

23. Nadh, R. V. and Sireesha, M. (2015). Kinetics and mechanism of Ru (III) catalysed and uncatalysed oxidation of DL-alanine by N-Bromosuccinimide. Bulg. Chem. Commun., 47(1), 13-21.

24. Gopalakrishnan, G. \& Hogg, J. L. (1985). Kinetic and mechanistic studies of the N-Bromosuccinimi-depromoted oxidative decarboxylation of glycine, DLalanine, and DL-valine. J. Org. Chem., 50(8), 1206-1212. https://pubs.acs.org/ doi/abs/10.1021/jo00208a012

25. Farook, N. A. M. (2006). Kinetics and mechanism of oxidation of 4-oxoacids by N-Bromosuccinimide in aqueous acetic acid medium. J. Iran. Chem. Soc., 3, 378-386.

26. Abdul Kudus, M. H. et al. (2019). Effect of water absorption on dielectric constant of TMD cured of carbonaceous filled epoxy composites. J. Phys. Sci., 30(Supp. 1), 101-107. https://doi.org/10.21315/jps2019.30.s1.6

27. Sharma, I. et al. (1995). Kinetics and mechanism of electron transfer reactions in aqueous solutions: Silver(I) catalyzed oxidation of aspartic acid by cerium (IV) in acid perchlorate medium. Int. J. Chem. Kin., 27(4), 311-319. https://doi .org/10.1002/kin.550270402 